\title{
EQUILÍBRIO SÓLIDO-LÍQUIDO NA PRECIPITAÇÃO DE LISOZIMA COM SAIS BIODEGRADÁVEIS
}

\author{
J. S. LÓPEZ VÉLEZ11, P. A. PESSOA FILHO² \\ ${ }^{1,2}$ Universidade de São Paulo / Escola Politécnica / Departamento de Engenharia Química \\ E-mail para contato: jslopezv@usp.br; pedro.pessoa@poli.usp.br
}

RESUMO - A precipitação e a cristalização de proteínas são operações amplamente usadas na indústria biotecnológica. Em ambos os casos, a informação fundamental é constituída pelos diagramas de fases, em que a solubilidade de uma proteína é apresentada com função de variáveis do sistema (temperatura, $\mathrm{pH}$, concentração salina). Neste trabalho, investigouse o equilíbrio sólido-líquido da lisozima de clara de ovo em soluções contendo sais biodegradáveis: citrato, tartrato e succinato de sódio. Dados experimentais de solubilidade foram obtidos como função do $\mathrm{pH}$ e da concentração de sal à temperatura constante. Estes dados foram ajustados por modelos termodinâmicos adequados. Observou-se que os três sais considerados são capazes de induzir o salting-out, ou seja, a diminuição da solubilidade da proteína pela adição de sal, sendo o succinato o sal mais efetivo em promover a precipitação. Esses resultados mostram que o citrato, tartrato e succinato de sódio são promissores como agentes precipitantes.

\section{INTRODUÇÃO}

Nos últimos tempos, a biotecnologia tem experimentado grande desenvolvimento no estudo, no desenvolvimento de processos e na produção de novos produtos químicos de origem biológica para múltiplas aplicações, seja como matéria-prima (em indústrias de cosméticos e alimentos, por exemplo) seja para uso direto como medicamentos (Basu et al. 2004). Na purificação de bioprodutos, os processos de separação (downstream) são parte vital. Dentre estas operações encontram-se duas em que o equilíbrio sólido-líquido tem importância: a precipitação e a cristalização. Ambas diferem na posição na sequência de purificação e na estrutura do sólido formado: a precipitação é considerada uma etapa inicial, de concentração, enquanto a cristalização é uma etapa mais refinada que garante uma maior pureza (Tam et al. 2011).

A precipitação é uma das técnicas mais antigas de concentração de proteínas; ela consiste na diminuição da solubilidade por meio da adição de um reagente ou outras mudanças no meio, de modo a promover a associação das regiões hidrofóbicas da molécula (Russo Krauss et al. 2013). Os agentes precipitantes utilizados nessa técnica podem ser, por exemplo, sais, solventes orgânicos ou polímeros. No caso de produtos usados diretamente em seres vivos como fármacos, suplementos alimentícios, entre outros, é necessário que o agente precipitante seja completamente retirado do sistema, ou que seja compatível com o organismo no qual será usado, e não cause nenhum efeito colateral. Por esta 


\section{9 a 22 de outubro de 2014 \\ Florianópolis/SC}

razão, são usados sais como cloreto de sódio, que estão presentes em diferentes processos orgânicos. Tendo em conta esta necessidade, existem novas alternativas, como são os sais derivados do ácido cítrico, como citrato de sódio, tartrato de sódio e succinato de sódio, os quais estão presentes em diferentes ciclos metabólicos próprios dos seres vivo.

Para predizer a precipitação de uma proteína por influência de um sal é necessário conhecer seu comportamento termodinâmico, isto é, o equilíbrio sólido-líquido. De modo geral, os dados experimentais relacionados compreendem a solubilidade da proteína em função das variáveis do sistema (concentração de sal, temperatura e pH). A diminuição de solubilidade por adição de sais é comumente denominada de salting out, e pode ser termodinamicamente interpretada em termos de grandezas mensuráveis (Melander and Horváth 1977).

O conhecimento da solubilidade, acoplada a modelos matemáticos de outras áreas como a cinética e a cristalografia, permite criar novas ferramentas para a projeção, otimização e operação de novos processos para a produção de proteína cristalina (Agena et al. 1999) (Espitalier et al. 2009). Muitos destes modelos são gerados por ajuste de parâmetros mediante o uso de dados experimentais, como por exemplo a equação de Cohn, que permite modelar o efeito de salting out (Melander and Horváth 1977).

\section{MATERIAIS E METODOS}

Lisozima de ovo de galinha com 92,5\% de pureza foi obtida da Sigma Aldrich. Os sais tartrato de sódio, citrato de sódio e succinato de sódio, acido cítrico, hidróxido de sódio foram também adquiridos da Sigma Aldrich. Acido clorídrico fora fornecido pela Merk. Todas as soluções de proteína e tampão foram preparadas com água deionizada, purificada com o sistema Millipore Milli-Q system $(>18,2 \mathrm{~m} \Omega \cdot \mathrm{cm})$. Todos os experimentos foram realizados a $25^{\circ} \mathrm{C}$, e à temperatura foi mantida constante por meio de banho termostatizado Láctea com controlador de temperatura Julabo EC $\left( \pm 0,1^{\circ} \mathrm{C}\right)$. A centrifugação das amostras foi feita em uma centrifuga refrigerada Jouan. As concentrações de proteína foram determinadas usando o espectrofotômetro Nanodrop 2000/2200c marca Thermoscientific, por meio da medida de absorbância em comprimento de onda de $280 \mathrm{~nm}$.

Os sais foram dissolvidos em concentrações próximas ao limite de solubilidade; como exemplo, o limite de solubilidade do tartrato de sódio é 27,6\% w/w. As duas soluções foram então misturadas em diferentes proporções para obter diferentes concentrações de tartrato de sódio (aproximadamente de 10 a $21 \%$ w/w). A mesma solução de tartrato de sódio foi usada para a preparação das soluções a diferentes valores de $\mathrm{pH}$, utilizando diferentes proporções de hidróxido de sódio $2 \mathrm{M}$ e ácido clorídrico 1M. De forma análoga, citrato e succinato de sódio foram dissolvidos até um valor próximo à solubilidade em água (29,8\% w/w e 19,8\% w/w, respectivamente). As soluções foram redissolvidas em diferentes proporções para atingir diferentes concentrações de sal. Estas soluções em máxima concentração também foram usadas para a preparação de soluções a diferentes valores de $\mathrm{pH}$. 


\section{9 a 22 de outubro de 2014 \\ Florianópolis/SC}

Para os experimentos de solubilidade, a lisozima cristalizada foi adicionada em amostras de 0,5 g de solução salina (tartrato, citrato e succinato de sódio) de diferentes concentrações de sal até que o limite de solubilidade da proteína fosse atingido, isto é, até que não houvesse mais dissolução da proteína. As amostras foram, então, agitadas em um homogeneizador e mantidas à temperatura constante por oito dias. Caso fosse notada dissolução do precipitado, uma quantidade maior de proteína era adicionada. Finalizado o período de oito dias sem dissolução do precipitado, as amostras foram centrifugadas a $16000 \mathrm{~g}$ por 45 minutos à temperatura constante de $25^{\circ} \mathrm{C}$. Todos os experimentos foram realizados em triplicata. A concentração de proteína foi medida pela absorbância da fase sobrenadante.

\section{RESULTADOS}

\subsection{Solubilidade de Lisozima em função do $\mathbf{p H}$}

Os dados da solubilidade da lisozima em função do pH são mostrados na Figura 1. Estes experimentos foram realizados à temperatura de $25^{\circ} \mathrm{C}$ e força iônica constante, equivalente à concentração de sal próxima a correspondente saturação em água (citrato de sódio, 0,298 w/w, succinato de sódio, 0,198 w/w, e tartrato de sódio, 0,276 w/w).

A solubilidade da lisozima em água pura é da ordem de $300 \mathrm{mg} / \mathrm{mL}$. Para um valor de $\mathrm{pH}$ próximo a 10,3, o succinato de sódio tem a maior capacidade de induzir o salting-out, seguido pelo citrato de sódio e o tartrato de sódio. Todos as sais tendem a um mínimo de solubilidade perto do ponto isoelétrico da lisozima (que corresponde a um $\mathrm{pH}$ de 11,3). $\mathrm{O}$ tartrato de sódio apresenta outro mínimo em um pH ácido (próximo a 4), o que indica que o ânion, nessa condição, passa a atuar como contra-íon. É sabido que, para valores de $\mathrm{pH}$ muito abaixo do ponto isoelétrico, os sais podem seguir uma série inversa de Hofmeister, em função principalmente deste fato (Watanabe et al. 2009).

\subsection{Solubilidade de Lisozima em função de concentração de sal}

Na Figura 2 apresentam-se os resultados obtidos para a solubilidade da lisozima em função da concentração de sal. Os experimentos foram realizados a $25^{\circ} \mathrm{C}$ e a $\mathrm{pH}$ constante (citrato 7,1 , tartrato 5,94, e succinato, 6,43). O limite superior da concentração de sal novamente foi dado por sua solubilidade em água.

O citrato de sódio parece apresentar uma tendência em solubilizar a lisozima em valores menores de concentração $(10 \% \mathrm{w} / \mathrm{w})$. Entretanto, o chamado salting in não foi observado de modo experimental, principalmente em razão da alta solubilidade da lisozima em solução isenta de sal. Observa-se que o succinato de sódio é o sal com maior capacidade de induzir o salting out, seguido pelo tartrato e pelo citrato, como pode ser visto considerando-se uma solução com a mesma concentração de sal. 


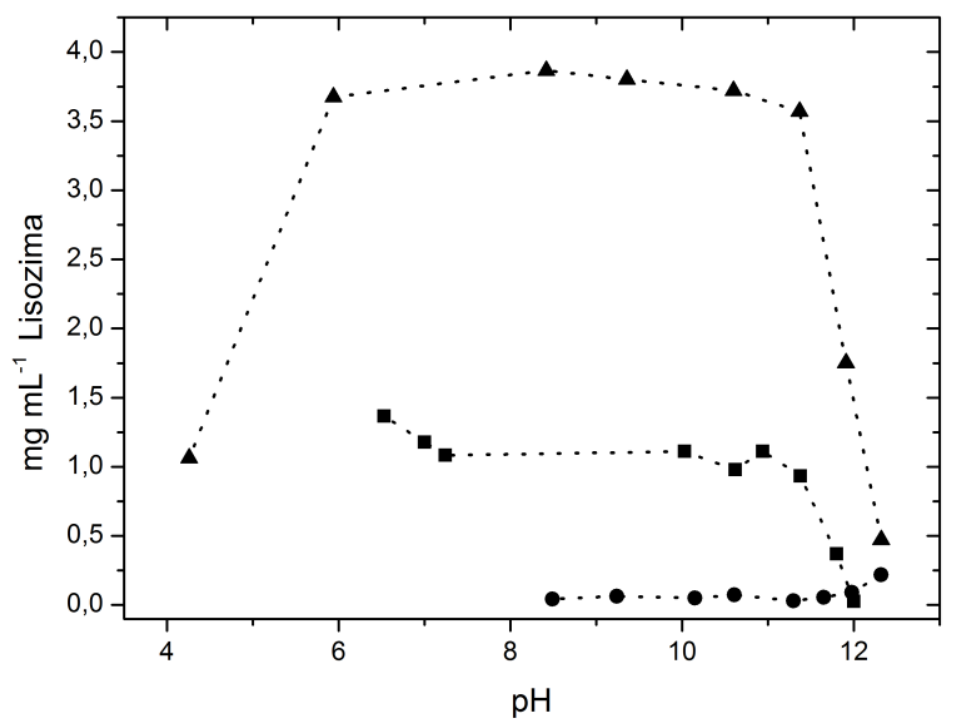

Figura 1 - Solubilidade da Lisozima em função do $\mathrm{pH}$ e força iônica constante: quadrados cheio citrato de sódio; triângulos fechados, tartrato de sódio e círculos, succinato de sódio. Linhas par: guiar os olhos

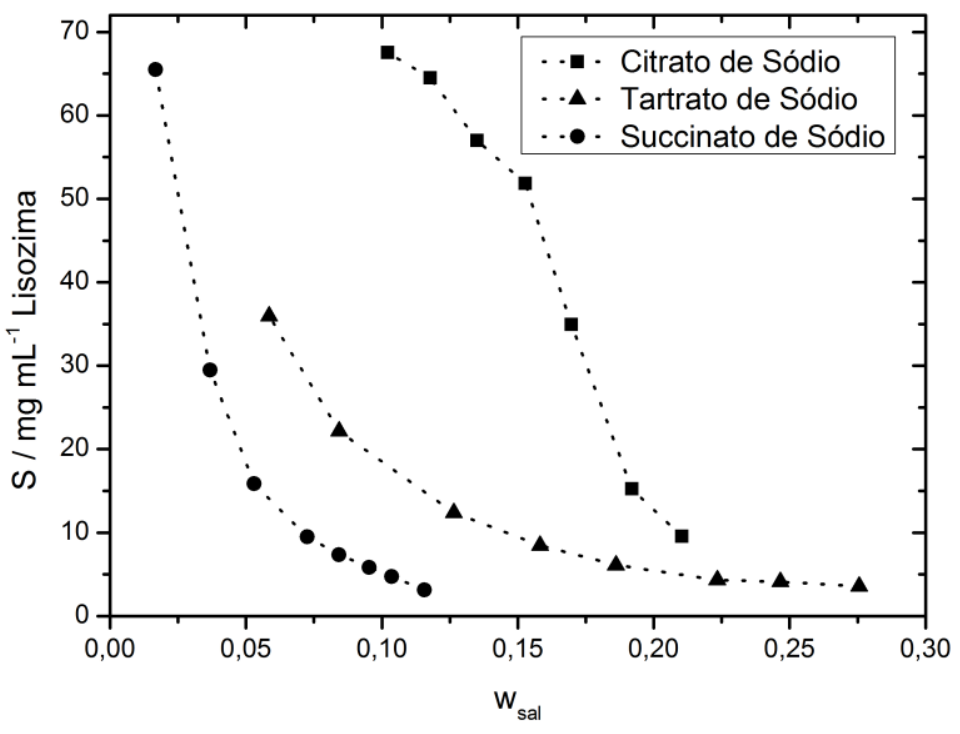

Figura 2 - Solubilidade da Lisozima em função da concentração de sal a $25^{\circ} \mathrm{C}$ e pH de: citrato sódio7,1, tartrato de sódio 5,94 e succinato de sódio 6,43. Linhas para guiar os olhos. 
A solubilidade de lisozima em função da força iônica pode ser expressa em termos da equação de Cohn (Melander and Horváth 1977):

$$
\ln (S)=\beta+K_{S} I
$$

em que a solubilidade mássica $S$ é escrita em função da força iônica $I$. O parâmetro $K_{s}$ é chamado de constante de salting out, e é o parâmetro que define a capacidade de um sal em induzir o salting out. Na Tabela 1 são apresentados os resultados obtidos no ajuste dos parâmetros para a equação de Cohn para os três sais em função da força iônica.

Tabela 1 - Constantes de Salting Out

\begin{tabular}{cccc}
\hline & $\boldsymbol{\beta}$ & $\mathbf{K}_{\mathbf{s}}$ & $\mathbf{R}^{2}$ \\
\hline Citrato & 1,7141 & $-1,3056$ & 0,988 \\
Tartrato & $-2,9310$ & $-0,6909$ & 0,953 \\
Succinato & $-2,4129$ & $-1,5816$ & 0,984 \\
\hline
\end{tabular}

Observa-se, nesse caso, que o maior valor absoluto da constante de salting out é obtido para o succinato de sódio, corroborando numericamente as observações visuais. $O$ valor da constante de salting out para o succinato de sódio é do mesma ordem de grandeza que para outros sais usados em na precipitação de lisozima (Watanabe et al. 2009), o que ajuda a estabelecer este sal como uma alternativa promissora como agente precipitante.

\section{CONCLUSÕES}

Os sais estudados derivados do ácido cítrico (citrato, succinato e tartrato de sódio) são capazes de induzir o salting-out da lisozima em solução aquosa, e podem ser considerados como promissores agentes precipitantes. Destes, o succinato mostrou-se o mais efetivo em termos da diminuição da solubilidade, quantificada pela constante de salting out. Observou-se que em valores de $\mathrm{pH}$ muito abaixo do ponto isoelétrico existe a possibilidade de formação de complexos entre o tartrato e a lisozima, fato inferido pela diminuição da solubilidade observada. Entretanto, essa diminuição é muito menor do que ocorre, por exemplo, com sulfatos, e pode significar que a forma precipitada é formada apenas por um hidrato proteico, embora mais estudos sejam necessários para confirmar esse fato. 


\section{REFERÊNCIAS}

Agena SM, Pusey ML, Bogle ID (1999) Protein solubility modeling. Biotechnol Bioeng 64:14450 .

Basu SK, Govardhan CP, Jung CW, Margolin AL (2004) Protein crystals for the delivery of biopharmaceuticals. Expert Opin Biol Ther 4:301-17.

Espitalier F, Cheng YC, Lenhoff a. M (2009) Mechanism of formation of lysozyme crystals in concentrated ammonium sulfate solution from concentration profiles and equilibria: Influence of the 2nd osmotic virial coefficient. Powder Technol 190:112-117.

Melander W, Horváth C (1977) Salt effect on hydrophobic interactions in precipitation and chromatography of proteins: an interpretation of the lyotropic series. Arch Biochem Biophys 183:200-215.

Russo Krauss I, Merlino A, Vergara A, Sica F (2013) An overview of biological macromolecule crystallization. Int J Mol Sci 14:11643-91.

Tam SK, Chan HC, Ng KM, Wibowo C (2011) Design of Protein Crystallization Processes Guided by Phase Diagrams. Ind Eng Chem Res 50:8163-8175.

Watanabe EO, Popova E, Miranda EA, et al. (2009) Phase equilibria for salt-induced lysozyme precipitation: Effect of salt type and temperature. Fluid Phase Equilib 281:32-39. 